\title{
Renin angiotensin system and gender differences in dopaminergic degeneration
}

Ana I Rodriguez-Perez, Rita Valenzuela, Belen Joglar, Pablo Garrido-Gil, Maria J Guerra and

Jose L Labandeira-Garcia*

\begin{abstract}
Background: There are sex differences in dopaminergic degeneration. Men are approximately two times as likely as premenopausal women of the same age to develop Parkinson's disease (PD). It has been shown that the local renin angiotensin system (RAS) plays a prominent role in sex differences in the development of chronic renal and cardiovascular diseases, and there is a local RAS in the substantia nigra and dopaminergic cell loss is enhanced by angiotensin via type 1 (AT1) receptors.
\end{abstract}

Results: In the present study, we observed that intrastriatal injection of 6-hydroxydopamine induced a marked loss of dopaminergic neurons in the substantia nigra of male rats, which was significantly higher than the loss induced in ovariectomized female rats given estrogen implants (i.e. rats with estrogen). However, the loss of dopaminergic neurons was significantly lower in male rats treated with the AT1 antagonist candesartan, and similar to that observed in female rats with estrogen. The involvement of the RAS in gender differences in dopaminergic degeneration was confirmed with AT1a-null mice lesioned with the dopaminergic neurotoxin MPTP. Significantly higher expression of AT1 receptors, angiotensin converting enzyme activity, and NADPH-oxidase complex activity, and much lower levels of AT2 receptors were observed in male rats than in female rats with estrogen.

Conclusions: The results suggest that brain RAS plays a major role in the increased risk of developing PD in men, and that manipulation of brain RAS may be an efficient approach for neuroprotective treatment of PD in men, without the feminizing effects of estrogen.

Keywords: angiotensin, estrogen, menopause, NADPH-oxidase complex, neurodegeneration, oxidative stress, Parkinson, sex differences

\section{Background}

There are sex differences in dopaminergic (DA) degeneration, as observed in animal models as well as clinical and epidemiological reports on Parkinson's disease (PD). The higher risk of developing PD in men than in premenopausal women of the same age is well-established; men are approximately two times as likely as women to develop the disease [1-3]. However, the mechanisms responsible for this difference have not been clarified [4]. It has been shown that the renin angiotensin system (RAS) plays a prominent role in sex differences in the development of chronic renal and cardiovascular

\footnotetext{
* Correspondence: joseluis.labandeira@usc.es Department of Morphological Sciences, Networking Research Center on Neurodegenerative Diseases (CIBERNED), University of Santiago de Compostela, Santiago de Compostela, E-15782 Spain
}

diseases. The peptide angiotensin II (AII), via type 1 (AT1) receptors is one of the most important known inflammation and oxidative stress inducers, and produces reactive oxygen species (ROS) by activation of the NADPH-oxidase complex [5-7], which is the most important intracellular source of ROS apart from mitochondria [8,9]. Interestingly, RAS activity is higher in kidneys and cardiovascular tissues from males than in the same tissues from females [10-13], and males and females respond differently to stimulation and inhibition of RAS $[14,15]$. Furthermore, it has been shown that expression of vascular and renal AT1 receptors, as well as the balance between AT1 and AT2 receptors may be modulated by sex hormones, and a major role for RAS in the gender differences in the development of chronic renal and cardiovascular diseases has been proposed

\section{Biomed Central}


[10-12]. Several studies have revealed that estrogenmediated down-regulation of the renin-angiotensin system (RAS) mediates beneficial effects of estrogen (E2) in several tissues [16-18]. Furthermore, there is substantial evidence that androgens may upregulate RAS activity and therefore amplify gender-related differences $[10,19,20]$.

The brain possesses a local RAS [21,22]. We have previously shown that there is a local RAS in the substantia nigra and that DA cell loss is enhanced by AII via AT1 receptors and activation of the microglial NADPH-oxidase complex in several animal models of PD [23-25]. However, it is not known if there are differences between males and females in RAS activity in the substantia nigra, which may also be involved in the higher risk of developing PD in men than in premenopausal women. In the present study, we compared the effects of the DA neurotoxin 6-hydroxydopamine (6-OHDA) on DA neuron degeneration in male rats and rats with high stable levels of E2 (i.e. similar to proestrus), and investigated the nigral RAS in both groups of animals. Several studies have shown that the risk of developing several E2-related diseases varies with the menstrual cycle in women $[26,27]$. However, normal rat females have a 4-day estrous cycle, with a very short proestrus period (i.e. only 12 hours with high levels of E2). It is therefore expected that most of these rats will have low levels of E2 when killed, and during most of the 6OHDA lesion period (two weeks), and are thus not suitable for comparison with male rats as regards understanding gender differences in vulnerability to neurotoxins in humans. Finally, the involvement of RAS in the observed gender differences in DA neuron susceptibility to the neurotoxin was confirmed by inhibition of AT1 receptors with the AT1 receptor antagonist candesartan in 6-OHDA treated male rats, and by a second experimental approach using AT1 deficient mice lesioned with the DA neurotoxin MPTP (1-methyl-4phenyl-1,2,3,6-tetrahydropyridine).

\section{Results}

Intrastriatal injection of 6-OHDA induced a similar and marked loss of DA neurons in the substantia nigra of male rats and female rats without estrogen (i.e. ovx rats), which was significantly higher than that induced by 6-OHDA in female rats with estrogen (ovx + E2). Interestingly, however, the loss of DA neurons was significantly lower in male rats treated with the AT1 antagonist candesartan, and similar to that observed in female rats with estrogen. The present results therefore show that candesartan induced neuroprotection in male rats against 6-OHDA similar to that induced by estrogen in female rats. There was no significant difference in the number of $\mathrm{TH}$-ir neurons between control males injected with vehicle and male rats treated with candesartan alone (Figure 1). In order to confirm that 6 OHDA induced cell death and not only phenotypic down-regulation of tyrosine hydroxylase (TH) activity, series of sections through the entire substantia nigra of control rats and rats treated with 6-OHDA were counterstained with cresyl violet, and the total number of neurons in the SNc was estimated. The number of neurons in unlesioned females (ovx+E2; $12688 \pm 472)$ and males $(13067 \pm 540)$ was much higher than in 6OHDA-lesioned ovx females $(4318 \pm 441)$ or males $(4856 \pm 317)$, which was significantly lower than in females with estrogen (ovx+E2+6-OHDA; $7732 \pm 346)$ or males treated with candesartan (males+6-OHDA +cande; $8421 \pm 417)$. As expected, the number of Nisslstained neurons counted in Cresyl-violet stained sections was slightly higher than that of $\mathrm{TH}$-immunoreactive (TH-ir) neurons since some non-dopaminergic neurons located in the area of the SNc were also included.

The involvement of the RAS with regard to gender differences in DA degeneration was confirmed by using a second experimental approach in which AT1a-null mice were lesioned with the DA neurotoxin MPTP. Administration of MPTP induced a similar and marked loss of DA neurons in the substantia nigra of wild type (WT) male mice and WT female mice without estrogen (i.e. ovx WT mice), and was significantly higher than that induced by MPTP in female WT mice with estrogen (ovx WT+E2). However, the loss of DA neurons was significantly lower in male AT1a-null mice, and similar to that observed in female WT mice with estrogen (Figure 2). In order to confirm that MPTP induces cell death and not only phenotypic down-regulation of $\mathrm{TH}$ activity, series of sections through the entire substantia nigra of different groups of mice were counterstained with cresyl violet, and the total number of neurons in the SNc was estimated. The number of neurons in unlesioned females (ovx+E2; $14760 \pm 876)$, WT males and AT1a-null mice (14209 \pm 947 and $13976 \pm$ 756 , respectively) was much higher than in MPTPlesioned ovx females $(5815 \pm 698)$ or WT males $(6070 \pm$ $598)$, which was significantly lower than in females with estrogen (ovx+E2+MPTP; $8911 \pm 908)$ or AT1a-null males (AT1 ${ }^{-1}-+$ MPTP; $10553 \pm 681$ ), confirming that MPTP induced cell death and not TH-downregulation in the present experimental conditions.

Real time RT-PCR analysis revealed significantly higher expression of AT1 receptor mRNA (around $160 \%$ ) and much lower levels of AT2 mRNA (about $70 \%$ reduction) in male rats than in female rats with estrogen (Figure 3A). Similarly, WB studies revealed a significantly higher expression of AT1 receptors in male rats than in female rats with estrogen, and the expression of AT2 receptors was significantly lower (about 
A
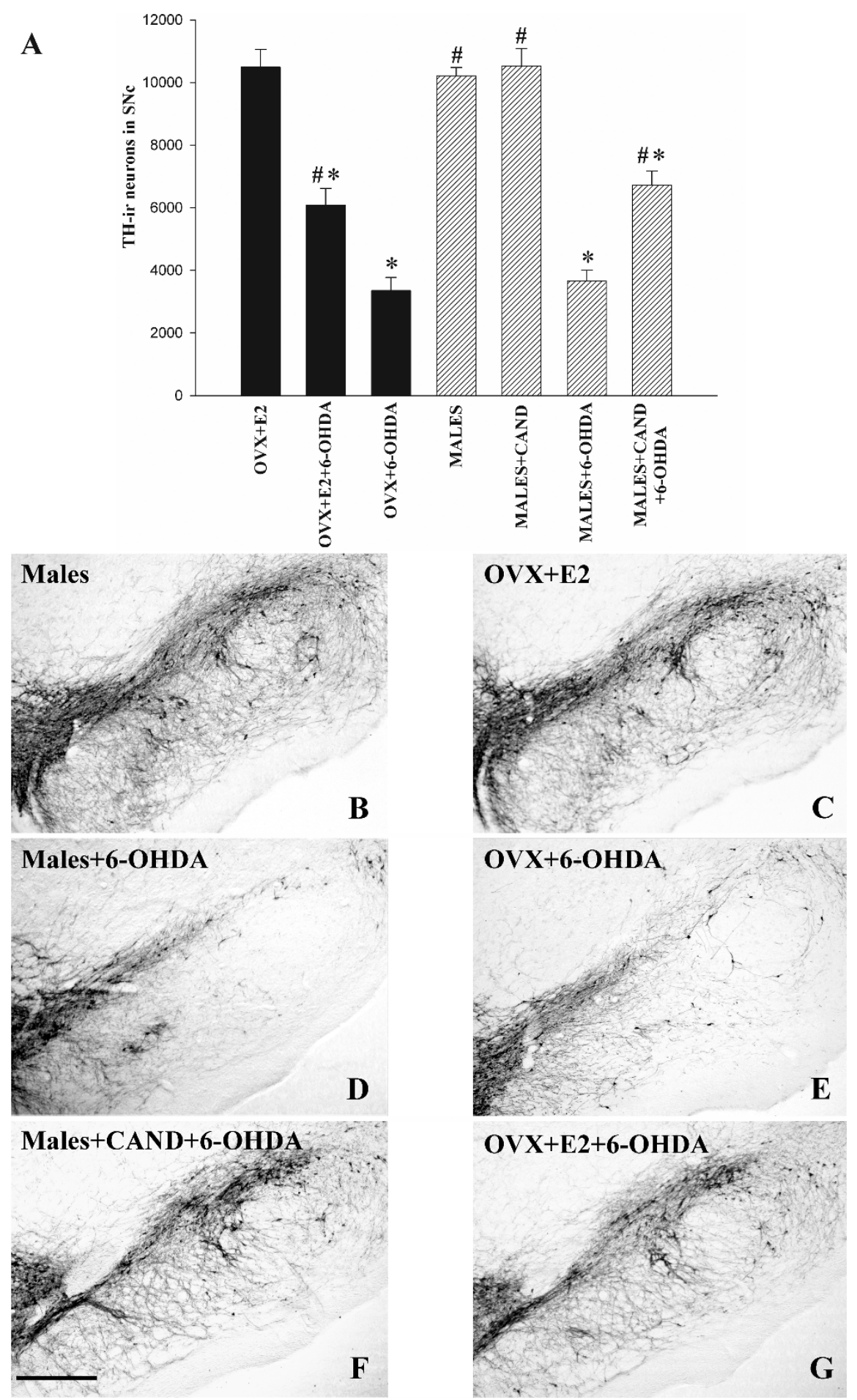

Figure 1 Dopaminergic neurons in the substantia nigra compacta (SNc) of rats. (A): Dopaminergic (TH-ir) neurons were counted in the SNc two weeks after intrastriatal injection of vehicle (i.e. controls; males and ovx+E2 females) or 6-OHDA in the different experimental groups. The dopaminergic neurons were quantified as the total number of TH-ir neurons in the SNc. Data are means \pm SEM. ${ }^{*} p<0.05$ relative to the corresponding saline-treated group (males or ovx+E2 females), ${ }^{*} \mathrm{p}<0.05$ relative to the group treated with 6-OHDA alone (i.e. males+6OHDA and ovx+6-OHDA). One-way ANOVA and Bonferroni post-hoc test. TH-ir, tyrosine hydroxylase immunoreactive. Representative photomicrographs of TH-ir neurons in non lesioned (i.e. control) males (B), females with estrogen (ovx+E2; C), 6-OHDA lesioned males (D) and 6-OHDA lesioned females without (E) and with estrogen $(\mathrm{G})$, as well as male rats lesioned with 6-OHDA and treated with the AT1 antagonist candesartan (cand; F). Scale bar: $500 \mu \mathrm{m}$. 


\section{A}
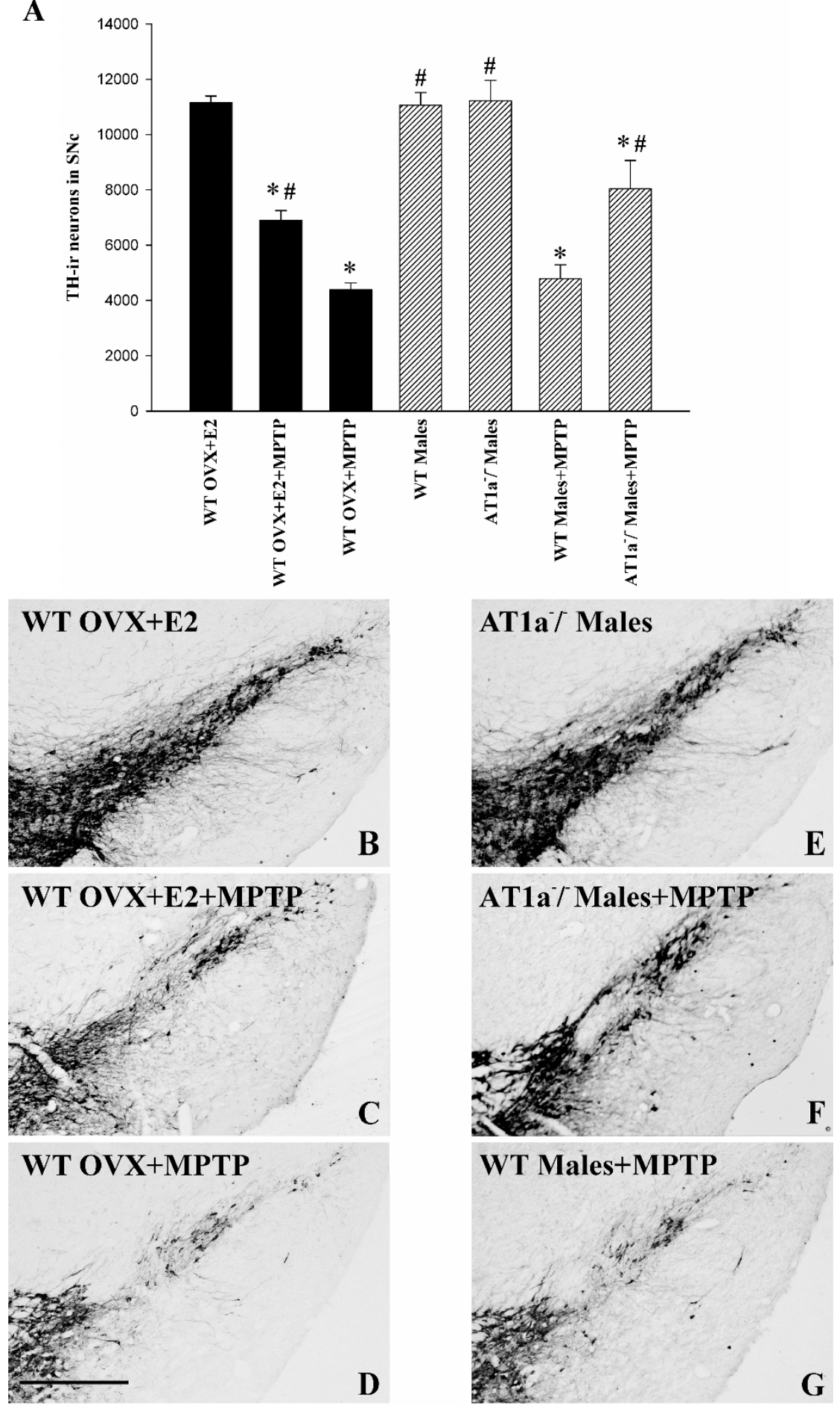

Figure 2 Dopaminergic neurons in the substantia nigra compacta (SNc) of mice. (A): Dopaminergic (TH-ir) neurons were counted in the SNc one week after the last intraperitoneal injection of saline (i.e. controls; WT and AT1a-null males and WT ovx+E2 females) or MPTP in the different experimental groups. The dopaminergic neurons were quantified as the total number of TH-ir neurons in the SNc. Data are means \pm SEM. ${ }^{*} p<0.05$ relative to the corresponding saline-treated group (males or ov $x+E 2$ females), ${ }^{*} p<0.05$ relative to the group treated with MPTP alone (i.e. WT males+MPTP and WT ovx+MPTP). One-way ANOVA and Bonferroni post-hoc test. (B-G): representative photomicrographs of TH-ir neurons in non lesioned WT females with estrogen (ovx+E2; B), MPTP lesioned WT females with (C) and without (D) estrogen, as well as nonlesioned AT1a-null male mice (AT1a ${ }^{-1} ;$ E), AT1a-null male mice lesioned with MPTP (F), and MPTP lesioned WT males (G). AT1 ${ }^{-1}$, AT1a-null mice; TH-ir, tyrosine hydroxylase immunoreactive; WT, wild type mice. Scale bar: $100 \mu \mathrm{m}$. 


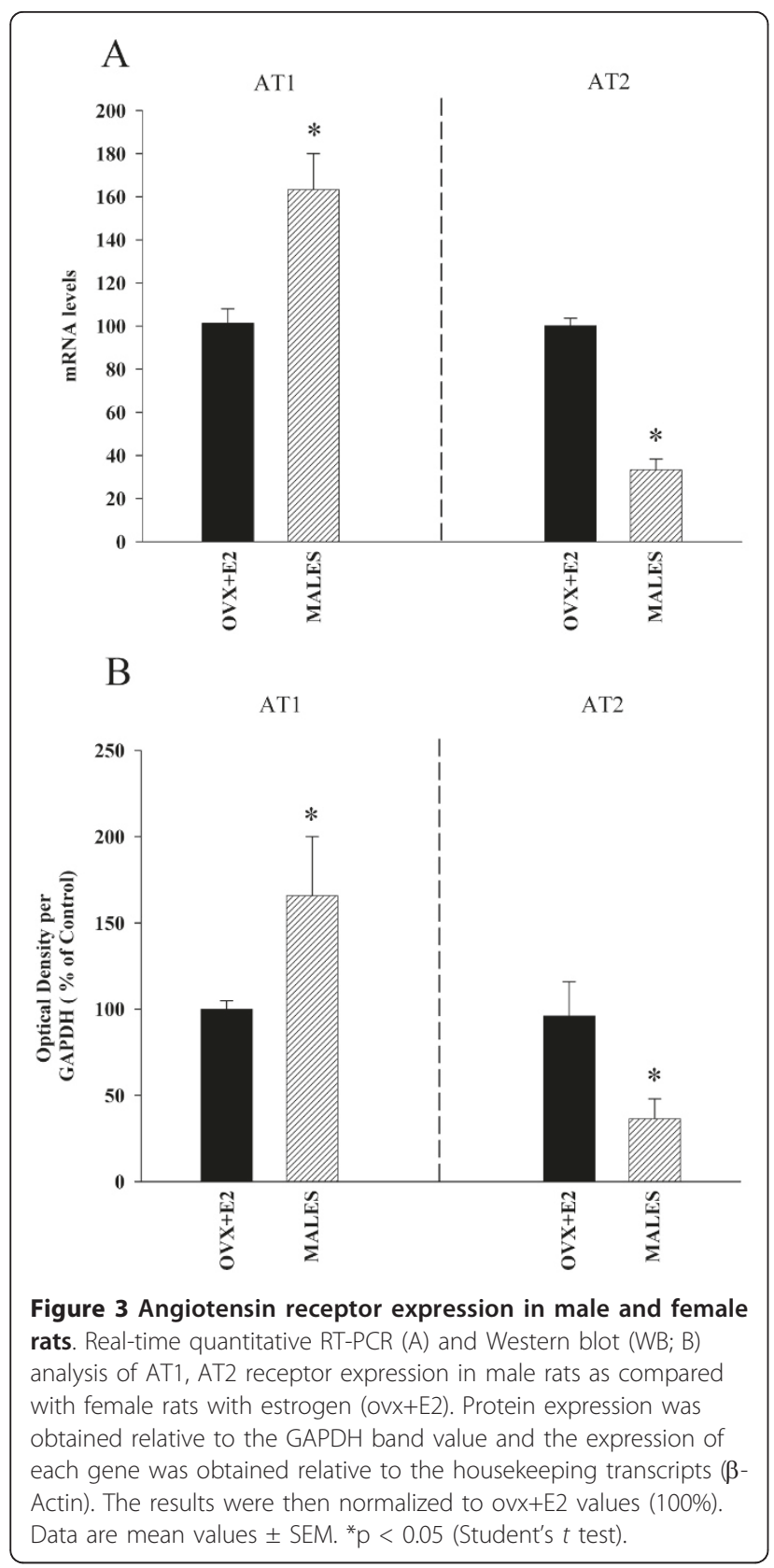

$65 \%$ reduction) in males (Figure 3B). ACE activity was significantly lower in female rats with estrogen than in males, which indicates increased AII production in males (Figure 4). In accordance with this, male rats showed significantly higher NADPH complex activity than female rats (Figure 5A). In previous studies, we observed the presence of several NADPH complex subunits, including $\mathrm{p} 47^{\text {phox }}$, in DA neurons and glial cells (microglia and astrocytes; see references 24 and 25 for details). The increased NADPH complex activation was confirmed by the increase in the expression of the $\mathrm{NADPH}$-oxidase subunit $\mathrm{p} 47^{\text {phox }}$ in males (Figure $5 \mathrm{~B}$ ).

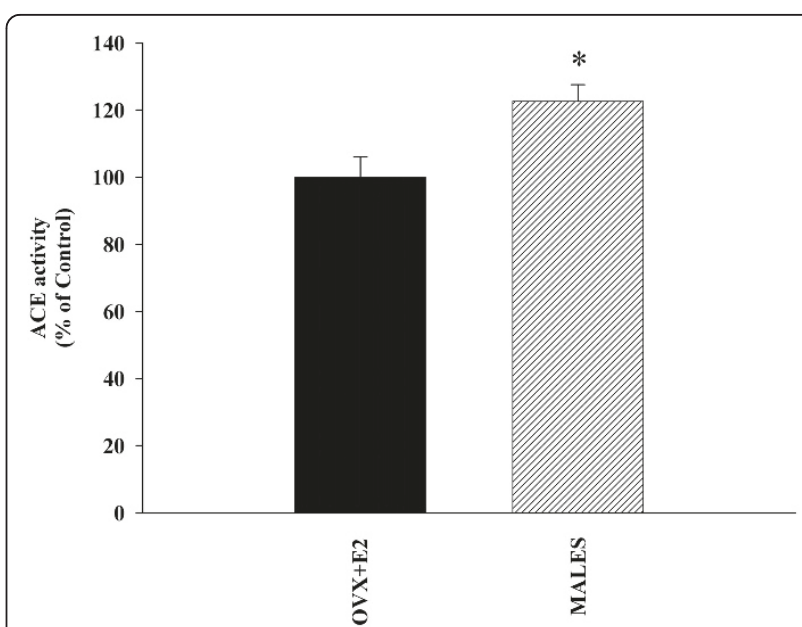

Figure 4 Activity of the angiotensin converting enzyme (ACE) in male and female rats. ACE activity in the ventral mesencephalon of males and female rats with estrogen (ovx +E2). ACE activity was significantly higher in male rats. Data were obtained as nmoles of his-leu produced per milligram of protein per minute and the results were then normalized to the values for ovx+E2 females (100\%). Data are means \pm SEM. ${ }^{*} p<0.05$ (Student's $t$ test).

Expression of the NADPH-oxidase cytosolic subunit $\mathrm{p} 47^{\mathrm{phox}}$ is an indicator of the level of activation of the $\mathrm{NADPH}$-oxidase complex. The NADPH-oxidase complex is composed of membrane-bound subunits and cytosolic subunits such as $\mathrm{p} 47^{\mathrm{phox}}$, which is considered a key subunit for NADPH-oxidase activation [28]. Translocation of cytosolic subunits to the membrane, which leads to generation of ROS is a necessary step for $\mathrm{NADPH}$-oxidase activation. The level of the NADPHoxidase subunit $\mathrm{p} 47^{\text {phox }}$ expression is correlated with $\mathrm{NADPH}$-oxidase activity and NADPH-derived superoxide formation [7,29]. Finally, we confirmed that inhibition of AT1 receptors with candesartan induced a decrease in RAS activity in male rats. Candesartan induced a significant increase in the expression of AT2 receptors, as well as a decrease in the expression of the $\mathrm{NADPH}$-oxidase subunit $\mathrm{p} 47^{\text {phox }}$. Changes in ACE activity were statistically not significant (Figure 6).

In previous studies, we observed AT1 and AT2 receptors in DA neurons and glial cells (astrocytes and microglia), and that AII induces microglial activation and DA cell death, via AT1 receptors and activation of the NADPH complex (see references 24 and 25 for details), which may explain the greater effect of DA neurotoxins observed in males than in female rats with estrogen. In order to confirm that the different response to 6-OHDA was associated with inhibition of the 6-OHDA-induced microglial response, we analyzed the expression of OX6 in the substantia nigra, as a marker for activated microglia. Control rats (i.e. ovx $+\mathrm{E} 2$ females and males injected 


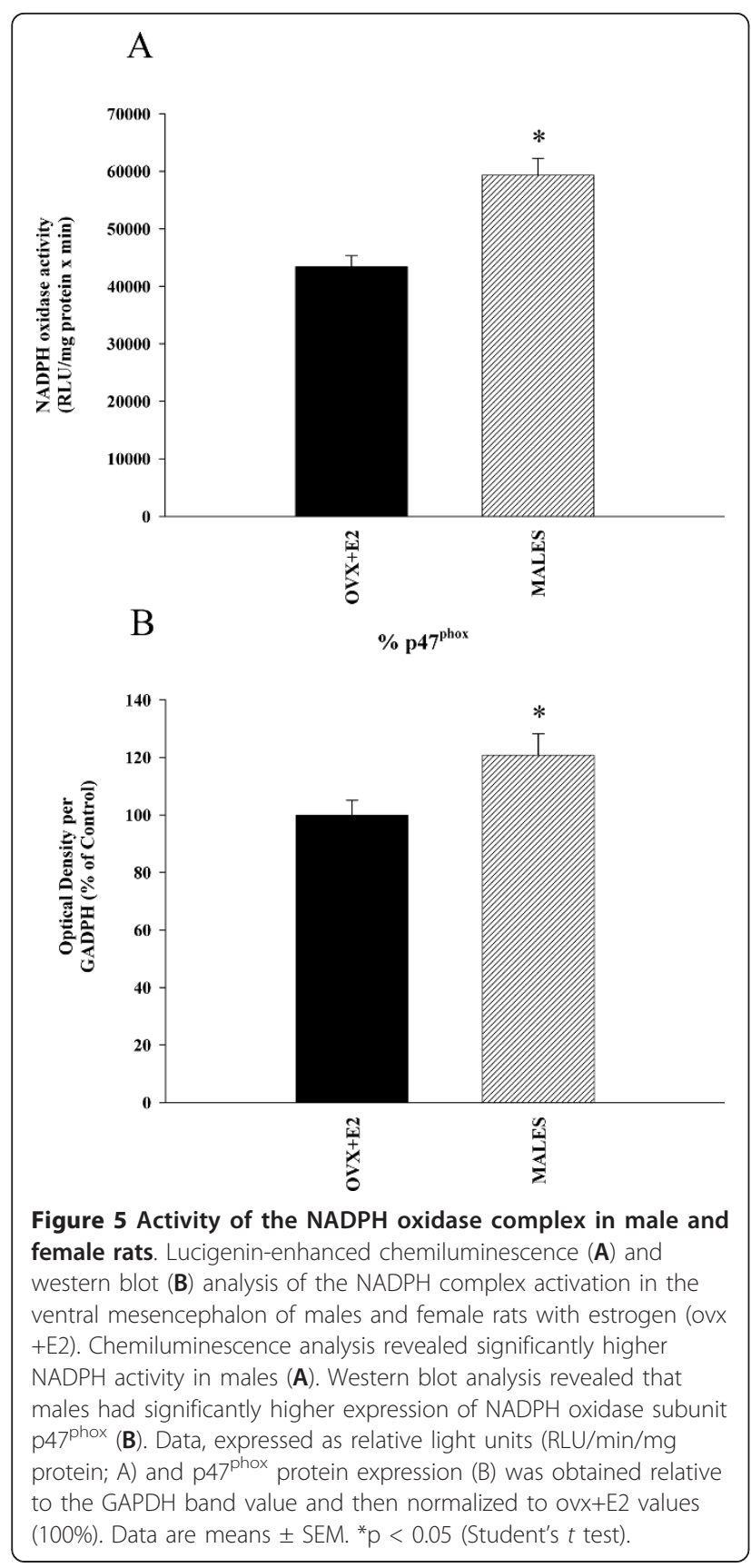

with vehicle) showed minimal microglial activation. In male rats and ovx female rats injected with 6-OHDA, microglial activation was much higher than in controls. However, 6-OHDA-induced microglial activation was significantly lower in male rats treated with candesartan (males+cand+6-OHDA) and in female rats with estrogen (ovx+E2+6-OHDA; Figure 7).

\section{Discussion}

PD is usually considered a multifactorial process in which low and apparently non-toxic doses of several

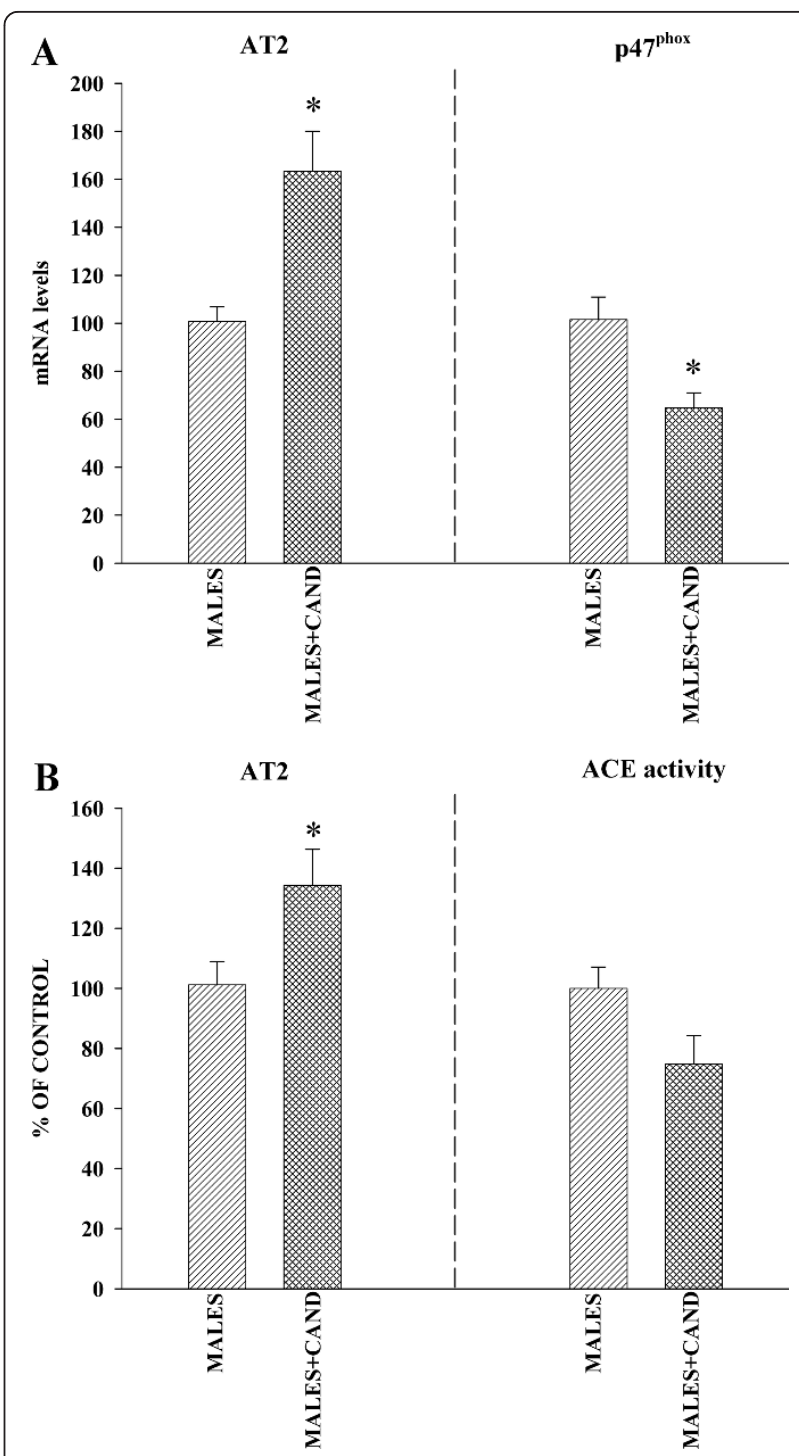

Figure 6 Analysis of changes induced by treatment candesartan in male rats. Real-time quantitative RT-PCR (A) and Western blot (WB; B) analysis, and activity of the angiotensin converting enzyme (ACE; $B)$ in male rats treated with candesartan. Blockage of AT1 receptors induced a significant increase in the expression of AT2 receptor and significant decrease in the expression of $\mathrm{NADPH}$ oxidase subunit $\mathrm{p} 47^{\mathrm{phox}}$ in comparison with the corresponding untreated male rats; the activity of the angiotensin converting enzyme (ACE) was not significantly lower than in untreated rats. Protein expression was obtained relative to the GAPDH band value and the expression of each gene was obtained relative to the housekeeping transcripts ( $\beta$-Actin). The results were then normalized to the values for control male rats (100\%). Data are means \pm SEM; ${ }^{*} p<0.05$ (Student's $t$ test).

pathogenic factors can act synergistically to cross the threshold of the DA cell degeneration [30] and oxidative stress and inflammation play major roles in the synergistic process [31-33]. Factors that increase the oxidative and inflammatory state of DA neurons may therefore 

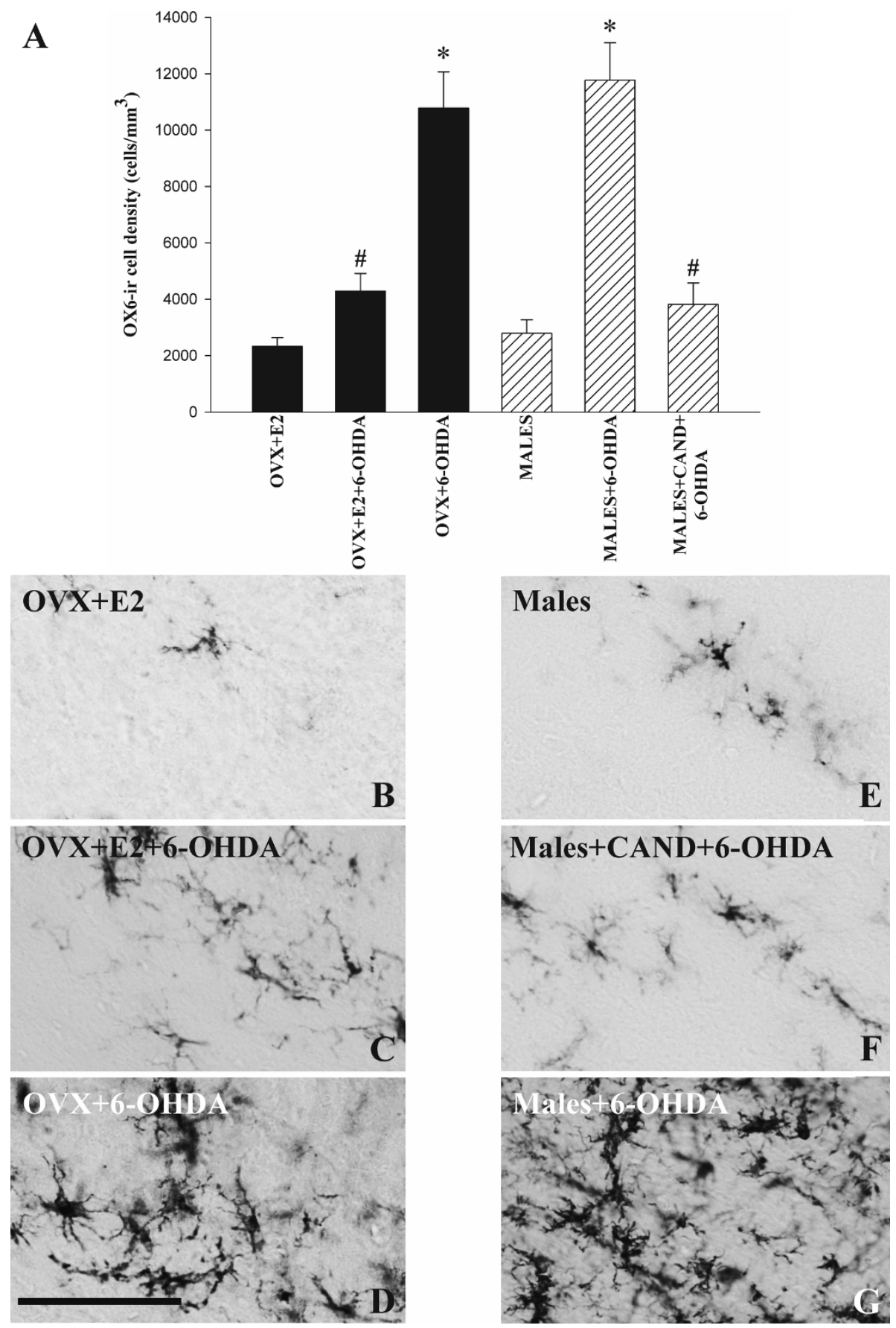

Figure 7 Activated microglial cells in the substantia nigra compacta (SNc). (A): density of OX6-positive cells in the SNc of female and male rats of different experimental groups treated with vehicle or 6-OHDA. The microglial cells were quantified as the number cells per $\mathrm{mm}^{3}$, and the data are means \pm SEM. ${ }^{*} p<0.05$ compared with rats treated with vehicle, ${ }^{\#} p<0.05$ compared with rats treated with 6-OHDA alone (One-way ANOVA and Bonferroni post-hoc test). (B-G): photomicrographs showing activated microglial cells at central levels of the substantia nigra in different experimental groups. Microglial activation was significantly higher in male rats and ovx female rats treated with 6-OHDA alone (D, G). Scale bar: $100 \mu \mathrm{m}$.

increase the risk of developing PD. In the present study we observed higher RAS activity in male rats and mice than in females with stable high levels of E2 (i.e. similar to proestrus); the observed upregulation of RAS activity may contribute to increased DA cell vulnerability in males. Male rats showed increased ACE activity, increased AT1 expression and decreased AT2 expression, as well as increased NADPH activity and $\mathrm{p} 47^{\text {phox }}$ 
expression. It is known that AII acts via AT1 receptors to induce inflammatory responses and to release high levels of ROS mainly by activation of the NADPH complex in vascular degenerative disease and other diseases mediated by oxidative stress and chronic inflammation $[7,34]$. In the nigrostriatal system of animal models of PD (i.e. rats lesioned with 6-OHDA and mice lesioned with MPTP), we have previously shown that brain AII induces activation of the NADPH complex via AT1 receptors, leading to increased neuroinflammation, oxidative stress and DA cell death [23-25].

The increased ACE activity in male rats leads to increased AII production. The observed upregulation of AT1 receptors in male rats may also contribute to NADPH activation and increased DA cell vulnerability. This is supported by the present experiments, in which we have observed that the enhanced susceptibility of DA neurons was significantly decreased by AT1 receptor inhibition with candesartan or deletion of AT1a receptors. Furthermore, the decrease in DA neuron susceptibility to MPTP observed in AT1a-null mice shows that the neuroprotective effect is related to the blockage of AT1 receptors and not to any other possible pharmacological effect of candesartan. It is particularly interesting that male rats also showed significantly fewer AT2 receptors than female rats, which may further enhance DA cell loss. AT1 and AT2 receptors have opposing effects and AT2 receptors counterbalance the deleterious effect of AT1 receptor stimulation, so that functional interactions between the two receptor subtypes and their specific distribution determines the AIIinduced effects [35], which in the case of male rats resulted in a pro-oxidative state as suggested by increased NADPH activity and $\mathrm{p} 47^{\text {phox }}$ expression. Interestingly, treatment with the AT1 antagonist candesartan induced a significant increase in AT2 receptor expression in males, which may also contribute to the decrease in NADPH activity and the neuroprotective effects of candesartan. An increase in AT2 expression after treatment with AT1 antagonists has also been observed in previous studies [36,37]. Furthermore, AT1 receptor blockage may also lead to preferential activation of the unopposed and upregulated AT2 receptors by similar levels of AII, as no significant change in ACE activity was observed.

We have previously shown NADPH expression in dopaminergic neurons and microglial cells. However, it appears that the AII-induced increase in microglial NADPH-oxidase activity plays a major role. It is known that in non-inflammatory cells, such as neurons, the NADPH complex produces only low rates of ROS for signaling function. In inflammatory cells such as microglia, NADPH activation produces high concentrations of ROS that are released extracellularly to kill invading microorganisms or cells $[8,9]$. In accordance with this, we observed that AII was not able to increase DA neuron death in the absence of microglial cells [24,25]. The present data showing differences in 6-OHDA-induced microglial activation in male and female rats confirmed the involvement of the microglial response in the sexual dimorphism of 6-OHDA neurotoxicity, and that inhibition of RAS activity with candesartan inhibits the enhanced microglial response in male rats.

The results of the present study (i.e. upregulation of RAS activity in male rats) suggest that RAS plays a major role in the higher risk in men than in premenopausal women of developing PD. It is known that neuroinflammation and microglial activation play a major role in the progression of PD [32,33,38]. AII via AT1 receptors is one of the most important inflammation and oxidative stress inducers, and a number of recent studies suggest that anti-inflammatory actions are at the core of estrogen-induced protective actions on different tissues $[16,39,40]$. Similarly, several studies have also shown that modulation of the glial neuroinflammatory response by estrogen is involved in the neuroprotective effects exerted by this hormone $[41,42]$, and the present results suggest that the brain RAS is also involved. The exact mechanism of interaction between E2 and RAS has not been clarified. It has also been suggested that E2 may inhibit the effects of AII by inhibiting NADPHderived ROS production [43], and that E2 may modulate Rho kinase signaling or other downstream pathways involved in RAS signaling [44].

In addition to the lack of estrogen, additional factors may increase RAS activity and the risk of developing PD in men. Several studies have shown that testosterone may upregulate RAS activity and therefore amplify gender-related differences $[10,19,20]$. It has been suggested that testosterone may modulate downstream pathways involved in RAS signaling such as Rho kinase [45]. Sex chromosomal complement may also influence AT2 receptor expression since the AT2 gene is located on the $\mathrm{X}$ chromosome [46]. Thus, it has been reported that AT2 receptors are absent from the kidneys of adult male rats [47], or are detected at lower levels than in females [48]. However, some studies have observed that sex differences in some RAS components in the kidney are E2-dependent and sex chromosome-independent [13]. As commented above, AT2 receptor stimulation acts in opposition to and in equilibrium with AT1 receptors, and exerts anti-inflammatory and antiproliferative effects in several tissues $[35,49]$. Furthermore, additional factors can further increase RAS activity and DA vulnerability in males. Firstly, aging is a particularly important factor, since advancing age itself is one of the most significant risk factors for the development of neurodegenerative diseases such as PD, and we have shown 
that RAS activity and oxidative stress and inflammation markers are significantly higher in aged male rats than in young male rats [50]. Secondly, we recently observed that an extensive DA denervation (i.e. 6-OHDA lesion) or functional DA depletion induced an increase in RAS activity and NADPH activity in the substantia nigra [51]. Similarly, several recent studies have revealed a counterregulatory interaction between the dopaminergic and RAS systems in several peripheral tissues, which plays a major role in degenerative changes in renal and cardiovascular systems [52-54]. This suggests that in males, an initial higher susceptibility to DA cell death and greater loss of DA terminals and DA depletion may lead to further increase in RAS activity and contribute to increased progression of PD in males.

\section{Conclusion}

The results suggest that brain RAS plays a major role in the increased risk of developing PD in men, and that manipulation of the brain RAS may be an efficient approach for neuroprotective or coadjutant treatment of PD in men since estrogen-like effects can be obtained without the feminizing effects of estrogen.

\section{Methods}

\section{Experimental design}

Young adult female and male Sprague-Dawley rats (ten weeks old at the beginning of the experiments; $\mathrm{n}=79$ ) and male C57BL-6 mice weighing 20-25 g (i.e. 7 weeks old; $n=43$ ) were used. Mice were wild type (Charles River, France) or homozygous mice deficient for AT1a (the major mouse AT1 isoform and the closest murine homolog to the single human AT1; [55]; Jackson Laboratory, Bar Harbor, ME, USA). All experiments were carried out in accordance with the "Principles of laboratory animal care" (NIH publication No. 86-23, revised 1985) and approved by the corresponding committee at the University of Santiago de Compostela. The animals were anesthetized with ketamine/xylazine anesthesia prior to surgery, and were fed with $2014 \mathrm{~S}$ Teklad Rodent Maintenance Diet (Harlan Laboratories) to minimize the occurrence of natural phytoestrogens. The animals were divided into 3 groups. Rats or mice in group A were females, which were ovariectomized (ovx) and given empty implants (see below; $\mathrm{n}=4$ rats and 6 mice). Rats or mice in group B were females, which were ovariectomized and given implants containing $17 \beta$ estradiol (ovx + E2; see below; $\mathrm{n}=27$ rats and 12 mice). Group $\mathrm{C}$ were male rats or mice (wild type or AT1anull mice) given empty implants $(n=48$ rats and 25 mice).

In the first series of experiments female or male rats ( $\mathrm{n}=35 ; 15$ females and 20 males) and female or male mice (wild type and AT1a-null mice; $\mathrm{n}=43 ; 15$ AT1a- null males, $10 \mathrm{WT}$ males, and $18 \mathrm{WT}$ females) were used to determine the effect of the presence of E2 or the AT1 receptor antagonist candesartan or AT1 deletion (i.e. inhibition of RAS activity by AT1 blockage) on the DA degeneration induced by the neurotoxin 6OHDA in rats and MPTP in mice in comparison with the corresponding controls injected with vehicle. A second series of experiments was carried out to investigate the levels of RAS components and markers of NADPHoxidase activity in male rats and female rats with estrogen (ovx+E2; $\mathrm{n}=44 ; 28$ males and 16 females; 2 nigral areas per rat). Rats and mice in the first series of experiments were injected intrastriatally with 6-OHDA (rats) or intraperitoneally with MPTP (mice) or vehicle (controls), then killed for immunohistochemical studies (i.e., quantification of dopaminergic cell death and activated microglia), as described below. Rats in the second series of experiments were killed by decapitation three weeks after ovariectomy and/or treatment with implants. The brains were rapidly removed and coronal slices of the mesencephalon were cut with a tissue chopper set to 1 $\mathrm{mm}$. To obtain substantia nigra compacta $(\mathrm{SNc})$, the individual $1 \mathrm{~mm}$ tissue sections were dissected on a precooled glass plate under a stereoscopic microscope (Leica M220). Both SNc was dissected according to Paxinos and Watson [56], frozen on dry ice, and stored separately (two SNc per rat) at $-80^{\circ} \mathrm{C}$ until processed. $75 \%$ of the nigras were used for expression of AT1 and AT2 receptors and expression of the NADPH-oxidase cytosolic subunit $\mathrm{p} 47^{\text {phox }}$ by Western Blot (WB) and RT-PCR studies, or Angiotensin converting enzyme (ACE) activity; 25\% of the nigras were processed for NADPH oxidase activity by lucigenin-enhanced chemiluminescence (see below).

\section{Estrogen and Candesartan administration}

Female rats or mice (groups A and B) were bilaterally ovariectomized through a dorsal incision and received Silastic implants placed subcutaneously in the midscapular region [57,58]. Rats received a single silastic implant prepared with Silastic ${ }^{\circledR}$ tubing $(1.47 \mathrm{~mm}$ ID $\times 1.95 \mathrm{~mm}$ OD, Dow Corning 508-006; VWR Scientific, Bridgeport, NJ), as described by Febo et al. [58]. Briefly, 5-mm-long sections of tubing were sealed at one end with Silastic silicone sealant (Dow Corning 732; VWR) and left to dry for $30 \mathrm{~min}$. The implants were then either filled with crystalline $17-\beta$ - estradiol (17- $\beta$ - estradiol benzoate; Sigma-Aldrich; group B) or were left empty (groups A and $C$ ); the open end was then sealed in the same way as the other end. Implants were air-dried and incubated in sterile saline for at least $12-16 \mathrm{~h}$ to allow the initial surge of high estradiol levels to be released before use. It has been observed that such implants achieve stable levels of plasma estradiol over $30 \mathrm{~d}$, with a release rate 
of $75-100 \mathrm{pg} / \mathrm{ml}$ per $24 \mathrm{~h}$ [58], as confirmed in our previous studies [59]. However, stable levels of E2 have also been found to persist for only 7-24 days [60]. Therefore, rats were killed 3 weeks after implantation (i.e., 2 weeks after 6-OHDA injection, see below). Mice received implants comprising a single 5-mm-long silastic tube prepared as described above and filled with $17-\beta$ - estradiol:cholesterol (1:1) or empty silastic implants (controls). This treatment provides plasma levels of $17-\beta$ estradiol of $87 \pm 9 \mathrm{pg} / \mathrm{ml}$. (i.e., similar to proestrus in normal mice) [61].

In addition, some male rats $(\mathrm{n}=16)$ received candesartan in their drinking water (Astra-Zeneca; $3 \mathrm{mg} / \mathrm{kg}$ / day) from 7 days before the empty implants were fitted until they were killed for immunohistochemistry or determination of levels of different RAS components. It has been reported that candesartan is the most effective AT1 antagonist in crossing the blood-brain barrier, and that low doses have little effect on blood pressure and block brain AII effects [62].

\section{Intrastriatal injection of 6-OHDA and intraperitoneal injection of MPTP}

One week after receiving empty or E2 implants, some rats in the different groups $(\mathrm{n}=35)$ were injected intrastriatally with 6-OHDA or vehicle. Thirty minutes prior to intrastriatal injection with 6-OHDA or vehicle, rats were treated with the selective inhibitor for the norepinephrine transporter desipramine (Sigma, $25 \mathrm{mg} / \mathrm{kg}$ i. p.) to prevent uptake of 6-OHDA by noradrenergic terminals. The rats were injected in the right striatum with $7 \mu \mathrm{g}$ of 6 -OHDA (in $3 \mu \mathrm{l}$ of saline containing $0.2 \%$ ascorbic acid; Sigma, USA). Stereotaxic coordinates were $1 \mathrm{~mm}$ anterior to bregma, $3.0 \mathrm{~mm}$ right of midline, and $5.5 \mathrm{~mm}$ ventral to the dura; tooth bar at -3.3 . Control animals were injected with $3 \mu \mathrm{l}$ of sterile saline alone. Rats were killed by chloral hydrate overdose 2 weeks post-lesion (i.e. 3 weeks post-implant). Previous studies on the time course of 6-OHDA lesions have shown that the loss of TH-immunoreactive (TH-ir) neurons is complete [63] or practically complete [64] 2 weeks after administration of intrastriatal injections. Although a few DA neurons may degenerate after the two-week period, we considered it more important to kill the rats before any possible loss of E2 levels (i.e. 3 weeks after implantation and 2 weeks after 6-OHDA injection).

One week after receiving empty or E2 implants, some mice in the different groups $(n=43)$ were injected with MPTP (Free base, Sigma; $30 \mathrm{mg} / \mathrm{kg} /$ day in saline, intraperitoneally; for 5 days; $\mathrm{n}=24$ ) or intraperitoneal vehicle $(\mathrm{n}=19)$. The mice were killed by chloral hydrate overdose one week after treatment with MPTP or vehicle (i.e. when the DA lesion is complete or practically complete) and then processed for histology.

\section{RNA extraction and real-time quantitative RT-PCR}

Total RNA from the nigral region was extracted with Trizol (Invitrogen), according to the manufacturer's instructions. Total RNA $(2.5 \mu \mathrm{g})$ was reverse-transcribed to cDNA with dNTPs, random primers, and Moloney murine leukemia virus reverse transcriptase (M-MLV; 200U; Invitrogen). Real-time PCR was used to examine relative levels of angiotensin receptors type 1 (AT1a) and type 2 (AT2) mRNA. Experiments were performed with a real-time iCyclerTM PCR platform (BioRad). $\beta$ Actin was used as housekeeping gene and was amplified in parallel with the genes of interest. The comparative $\mathrm{Ct}$ method was used to examine the relative mRNA expression. The expression of each gene was obtained as relative to the housekeeping transcripts. The data were then normalized to the values of the female group (ovx $+\mathrm{E} 2)$ of the same batch (100\%) to counteract any possible variability among batches. Finally, the results were expressed as mean \pm SEM. Primers sequences were as follows: for AT1a, forward 5'-TTCAACCTCTACGCCAGTGTG-3', reverse 5'-GCCAAGCCAGCCATCAGC3'; for AT2, forward 5'-AACATCTGCTGAAGACCAATAG-3', reverse 5'-AGAAGGTCAGAACATGGAAGG3; for $\mathrm{p} 47^{\mathrm{phox}}$, forward 5'-CCACACCTCTTGAA CTTCTTC-3', reverse 5'- CTCGTAGTCAGCGATGGC -3'; for $\beta$-actin, forward 5'-TCGTGCGTGACATTAAAGAG-3', reverse 5'-TGCCACAGGATTCCATACC-3'.

\section{Western blot analysis (WB) and ACE activity}

For WB, tissue was homogenized in RIPA buffer containing protease inhibitor cocktail (P8340, Sigma) and PMSF (P7626, Sigma). The homogenates were centrifuged and protein concentrations were determined with the Bradford protein assay. Equal amounts of protein were separated by $5-10 \%$ Bis-Tris polyacrylamide gel, and transferred to nitrocellulose membrane. The membranes were incubated overnight with primary antibodies (1:200) against AT1 receptor (sc-31181), AT2 receptor (sc-9040), and $\mathrm{p} 47^{\text {phox }}$ (sc-7660 all from Santa Cruz Biotechnology. The HRP conjugated secondary antibodies used were Protein A (NA9120V, GE Healthcare) and Protein G (18-161, Upstate-Millipore). Immunoreactivity was detected with an Immun-Star HRP Chemiluminescent Kit (170-5044, BioRad) and imaged with a chemiluminescence detection system (Molecular Imager ChemiDoc XRS System, BioRad). Blots were stripped and reprobed for anti-GAPDH (G9545, Sigma; $1: 25000)$ as loading control. In each animal, protein expression was measured by densitometry of the corresponding band and expressed as relative to the GAPDH band value. The data were then normalized to the values of the female-group of the same batch $(100 \%)$ to counteract any possible variability among batches. Finally, the results were expressed as means \pm SEM. 


\section{ACE and NADPH oxidase activity}

ACE activity in ventral mesencephalic tissue was assayed with hippuryl-L-histidyl-L-leucine (Hip-His-Leu; Sigma) as substrate, as described by Hemming et al. [65]. Fluorescence was assayed in 96-well plates in an Infinite M200 multiwell plate reader (TECAN; excitation, 355; emission, 535) and determined as nmoles of his-leu produced per milligram of protein per minute. The data were then normalized to the values of the female-group of the same batch (i.e., expressed as a percentage of the female values; $100 \%$ ). NADPH oxidase activity in ventral mesencephalic tissue was measured by lucigeninenhanced chemiluminescence with an Infinite M200 multiwell plate reader (TECAN), as described by Griendling et al. [66] and Hong et al. [67], respectively. Chemiluminescence was expressed as relative light units (RLU/min/mg protein).

\section{Immunohistochemistry. Dopaminergic neuron and microglia quantification}

The animals used for immunohistochemistry (i.e. those injected 6-OHDA or MPTP or vehicle) were first perfused with $0.9 \%$ saline and then with cold $4 \%$ paraformaldehyde in $0.1 \mathrm{M}$ phosphate buffer, $\mathrm{pH}$ 7.4. The brains were removed and subsequently washed and cryoprotected in the same buffer containing 20\% sucrose, and finally cut into $40 \mu \mathrm{m}$ sections on a freezing microtome. The sections were incubated for $1 \mathrm{~h}$ in $10 \%$ normal swine serum with $0.25 \%$ Triton X-100 in 20 $\mathrm{mM}$ potassium phosphate-buffered saline containing $1 \%$ bovine serum albumin (KPBS-BSA) and then incubated overnight at $4{ }^{\circ} \mathrm{C}$ with antibodies anti-tyrosine hydroxylase $(\mathrm{TH})$ as DA marker (mouse monoclonal anti-TH for rat sections, Sigma, 1:10 000; rabbit polyclonal antibodies to TH for mouse sections, Peel-Freez, 1:500), or anti-OX6 (a mouse monoclonal antibody directed against a monomorphic determinant of the rat major histocompatibility complex class II antigens, expressed by activated microglia but not by resting cells; $1: 200$; Serotec) as a marker of reactive microglia/macrophages. The sections were subsequently incubated, first for 60 min with the corresponding biotinylated secondary antibody, and then for $90 \mathrm{~min}$ with avidin-biotin-peroxidase complex (ABC, 1:100, Vector). Finally the labeling was revealed by treatment with $0.04 \%$ hydrogen peroxide and $0.05 \%$ 3-3'diaminobenzidine (DAB, Sigma). In all experiments the control sections, in which the primary antibody was omitted, were immunonegative for these markers.

The total number of TH-immunoreactive (TH-ir) neurons in the substantia nigra compacta was estimated by an unbiased stereological method (the optical fractionator). The stereological analysis was carried out with the Olympus CAST-Grid system (Computer Assisted
Stereological Toolbox; Olympus, Denmark). Uniform randomly chosen sections through the substantia nigra (every fourth section) were analyzed for the total number of TH-ir cells by means of a stereological grid (fractionator), and the nigral volume was estimated according to Cavalieri's method [68]. To confirm that 6-OHDA induces cell death, series of sections through the entire substantia nigra of control rats and rats treated with 6-OHDA were counterstained with Cresyl violet, and the total number of neurons in the substantia nigra was estimated by the unbiased stereology method described above for TH-ir cells. Neurons were distinguished from glial cells on a morphological basis, and neurons with visible nuclei were counted as above for TH-ir neurons. The number of OX6-ir cells (i.e. reactive microglia) was estimated using the Olympus CAST-Grid system and the unbiased stereological method described above for counting TH-ir neurons. At least four sections through the central SNc of each animal were measured. The density of OX6-ir cells $\left(\right.$ cells $/ \mathrm{mm}^{3}$ ) was determined by dividing the number of labeled cells by the volume that they occupied (see references 23 and 24 for details).

\section{Statistical analysis}

All data were obtained from at least three independent experiments and were expressed as means \pm SEM. Twogroup comparisons were analyzed by a Student's $t$ test and multiple comparisons were analyzed by one-way ANOVA followed by a post-hoc Bonferroni test. The normality of populations and homogeneity of variances were tested before each ANOVA. Differences were considered significant at $\mathrm{p}<0.05$. Statistical analyses were carried out with SigmaStat 3.0 from Jandel Scientific (San Rafael, CA, USA).

\section{List of abbreviations}

(6-OHDA): 6-hydroxydopamine; (ACE): Angiotensin converting enzyme; (All): Angiotensin II; (AT1): Angiotensin type 1 receptors; $\left(\mathrm{AT}^{-1}{ }^{-1}\right)$ : AT1a-null mice; (AT2) Angiotensin receptors type 2; (DA): Dopaminergic; (E2): Estrogen; (MPTP): 1-methyl-4-phenyl-1,2,3,6-tetrahydropyridine; (ovx): Ovariectomized; (PD): Parkinson's disease; (RAS): Renin angiotensin system; (ROS): Reactive oxygen species; (TH-ir): Tyrosine hydroxylase immunoreactive; (WB): Western Blot; (WT): wild type mice.

\section{Acknowledgements}

The authors thank Pilar Aldrey, Iria Novoa and Jose A. Trillo for their excellent technical assistance. The authors are thankful to Astra Zeneka for providing candesartan for the experiments. Funding: Spanish Ministry of Science and Innovation, Spanish Ministry of Health (RD06/0010/0013 and CIBERNED), Galician Government (XUGA) and FEDER.

\section{Authors' contributions}

AIR-P conducted the experiments with rats and performed quantitative PCR and statistical analysis; RV performed Western Blot and enzyme activity analysis; BJ performed the experiments with mice; PG-R performed the histological analysis, MJG and JL-G conceived the study and its design, supervised the project and edited the manuscript preparation. All authors have read and approved the manuscript. 


\section{Authors' information}

Laboratory of Neuroanatomy and Experimental Neurology, Dept. of Morphological Sciences, Faculty of Medicine, University of Santiago de Compostela. Networking Research Center on Neurodegenerative Diseases (CIBERNED, Instituto de Salud Carlos III), IDIS (Instituto de Investigaciones sanitarias de Santiago). Santiago de Compostela, Spain.

\section{Competing interests}

The authors declare that they have no competing interests.

Received: 7 April 2011 Accepted: 16 August 2011

Published: 16 August 2011

\section{References}

1. Mayeux R, Marder K, Cote L, Denaro J, Hemenegildo N, Mejia H, Tang MX, Lantigua R, Wilder D, Gurland B, et al: The frequency of idiopathic Parkinson's disease by age, ethnic group, and sex in northern Manhattan, 1988-1993. Am J Epidemiol 1995, 142:820-827.

2. Baldereschi M, Di Carlo A, Rocca WA, Vanni P, Maggi S, Perissinotto E, Grigoletto F, Amaducci L, Inzitari D: Parkinson's disease and parkinsonism in a longitudinal study: two-fold higher incidence in men. ILSA Working Group. Italian Longitudinal Study on Aging. Neurology 2000, 5:1358-1363.

3. Van Den Eeden SK, Tanner CM, Bernstein AL, Fross RD, Leimpeter A, Bloch DA, Nelson LM: Incidence of Parkinson's disease: variation by age, gender, and race/ethnicity. Am J Epidemiol 2003, 157:1015-1022.

4. González-Hernández T, Cruz-Muros I, Afonso-Oramas D, Salas-Hernandez J, Castro-Hernandez J: Vulnerability of mesostriatal dopaminergic neurons in Parkinson's disease. Front Neuroanat 2010, 4:140, PMID:21079748.

5. Seshiah PN, Weber DS, Rocic P, Valppu L, Taniyama Y, Griendling KK: Angiotensin II stimulation of $\mathrm{NAD}(\mathrm{P}) \mathrm{H}$ oxidase activity: upstream mediators. Circ Res 2002, 91:406-413.

6. Cai H, Griendling KK, Harrison DG: The vascular NAD(P)H oxidases as therapeutic targets in cardiovascular diseases. Trends PharmacolSci 2003, 24:471-478.

7. Touyz RM, Chen X, Tabet F, Yao G, He G, Quinn MT, Pagano PJ, Schiffrin EL: Expression of a functionally active gp 91 phox-containing neutrophil-type $\mathrm{NAD}(\mathrm{P}) \mathrm{H}$ oxidase in smooth muscle cells from human resistance arteries: regulation by angiotensin II. Circ Res 2002, 14:1205-1213.

8. Babior B: NADPH oxidase: An update. Blood 1999, 93:1464-1476.

9. Babior BM: NADPH oxidase. Curr Opin Immunol 2004, 16:42-47.

10. Fischer M, Baessler A, Schunkert H: Renin angiotensin system and gender differences in the cardiovascular system. Cardiovasc Res 2002, 53:672-677.

11. McGuire BB, Watson RW, Pérez-Barriocanal F, Fitzpatrick JM, Docherty NG: Gender differences in the renin-angiotensin and nitric oxide systems: relevance in the normal and diseased kidney. Kidney Blood Press Res 2007, 30:67-80.

12. Sandberg K, Ji H: Sex and the renin angiotensin system: implications for gender differences in the progression of kidney disease. Adv Ren Replace Ther 2003, 10:15-23.

13. Liu J, Ji H, Zheng W, Wu X, Zhu JJ, Arnold AP, Sandberg K: Sex differences in renal angiotensin converting enzyme 2 (ACE2) activity are $17 \beta-$ oestradiol-dependent and sex chromosome-independent. Biol Sex Differ 2010, 1:6.

14. Baiardi G, Macova M, Armando I, Ando H, Tyurmin D, Saavedra JM: Estrogen upregulates renal angiotensin II AT1 and AT2 receptors in the rat. Regul Pept 2005, 124:7-17.

15. Sullivan JC: Sex and the renin-angiotensin system: inequality between the sexes in response to RAS stimulation and inhibition. Am J Physiol Regul Integr Comp Physiol 2008, 294:R1220-1226.

16. Chen J, Yang S, Hu S, Choudhry MA, Bland Kl, Chaudry IH: Estrogen prevents intestinal inflammation after trauma-hemorrhage via downregulation of angiotensin II and angiotensin II subtype I receptor. Am J Physiol Gastrointest Liver Physiol 2008, 295:G1131-1137.

17. Dean SA, Tan J, O'Brien ER, Leenen FH: 17beta-estradiol downregulates tissue angiotensin-converting enzyme and ANG II type 1 receptor in female rats. Am J Physiol Regul Integr Comp Physiol 2004, 288:R759-766.

18. Nickenig G, Bäumer AT, Grohè C, Kahlert S, Strehlow K, Rosenkranz S, Stäblein A, Beckers F, Smits JF, Daemen MJ, Vetter H, Böhm M: Estrogen modulates AT1 receptor gene expression in vitro and in vivo. Circulation 1998, 97:2197-2201.
19. Ojeda NB, Royals TP, Black JT, Dasinger JH, Johnson JM, Alexander BT: Enhanced sensitivity to acute angiotensin II is testosterone dependent in adult male growth-restricted offspring. Am J Physiol Regul Integr Comp Physiol 2010, 298:R1421-1427.

20. Henriques T, Zhang X, Yiannikouris FB, Daugherty A, Cassis LA: Androgen increases AT1a receptor expression in abdominal aortas to promote angiotensin II-induced AAAs in apolipoprotein E-deficient mice. Arterioscler Thromb Vasc Biol 2008, 28:1251-1256.

21. McKinley MJ, Albiston AL, Allen AM, Mathai ML, May CN, McAllen RM, Oldfield BJ, Mendelsohn FAO, Chai S: The brain reenin-angiotensin system: location and physiological roles. Int I Biochem Cell Biol 2003, 35:901-918.

22. Saavedra JM: Brain angiotensin II: new developments, unanswered questions and therapeutic opportunities. Cell Mol Neurobiol 2005, 25:485-512.

23. Rey P, Lopez-Real A, Sanchez-Iglesias S, Muñoz A, Soto-Otero R, LabandeiraGarcia JL: Angiotensin type-1-receptor antagonists reduce 6hydroxydopamine toxicity for dopaminergic neurons. Neurobiol Aging 2007, 28:555-567.

24. Rodriguez-Pallares J, Rey P, Parga JA, Muñoz A, Guerra MJ, LabandeiraGarcia JL: Brain angiotensin enhances dopaminergic cell death via microglial activation and NADPH-derived ROS. Neurobiol Dis 2008, 31:58-73.

25. Joglar B, Rodriguez-Pallares J, Rodríguez-Perez Al, Rey P, Guerra MJ, Labandeira-Garcia JL: The inflammatory response in the MPTP model of Parkinson's disease is mediated by brain angiotensin: relevance to progression of the disease. J Neurochem 2009, 109:656-669.

26. Lloyd GW, Patel NR, McGing E, Cooper AF, Brennand-Roper D, Jackson G: Does angina vary with the menstrual cycle in women with premenopausal coronary artery disease? Heart 2000, 84:189-192.

27. Mills PJ, Ziegler MG, Nelesen RA, Kennedy BP: The effects of the menstrual cycle, race, and gender on adrenergic receptors and agonists. Clin Pharmacol Ther 1996, 60:99-104.

28. Li JM, Shah AM: Mechanism of endothelial cell NADPH oxidase activation by angiotensin II. Role of the p47phox subunit. J Biol Chem 2003, 278:12094-12100.

29. Rueckschloss U, Quinn MT, Holtz J, Morawietz H: Dose-dependent regulation of $\mathrm{NAD}(\mathrm{P}) \mathrm{H}$ oxidase expression by angiotensin II in human endothelial cells: protective effect of angiotensin II type 1 receptor blockade in patients with coronary artery disease. Arterioscler Thromb Vasc Biol 2002, 22:1845-1851.

30. Gao HM, Liu B, Zhang W, Hong JS: Synergistic dopaminergic neurotoxicity of MPTP and inflammogen lipopolysaccharide: relevance to the etiology of Parkinson's disease. FASEB J 2003, 17:1957-1959.

31. Andersen JK: Oxidative stress in neurodegeneration: cause or consequence. Nat Med 2004, 10:518-25.

32. Wu DC, Jackson-Lewis V, Vila M, Tieu K, Teismann P, Choi DK, Przedborski S: Blockade of microglial activation is neuroprotective in the 1-methyl-4phenyl-1,2,3,6-tetrahydropyridine mouse model of Parkinson disease. J Neurosci 2002, 22:1763-1771.

33. Wu D, Teisman P, Tieu K, Vila M, Jackson-Lewis V, Ischiropoulos $H$, Przedborski S: NADPH oxidase mediates oxidative stress in the 1-methyl4-phenyl-1,2,3,6-tetrahydropyridine model of Parkinson"s disease. Proc Natl Acad Sci USA 2003, 100:6145-6150.

34. Qin L, Liu Y, Wang T, Wei SJ, Block ML, Wilson B, Liu B, Hong JS: NADPH oxidase mediates lipopolysaccharide-induced neurotoxicity and proinflammatory gene expression in activated microglia. J Biol Chem 2004, 279:1415-1421.

35. Sohn HY, Raff U, Hoffmann A, Gloe T, Heermeier K, Galle J, Pohl U: Differential role of angiotensin II receptor subtypes on endothelial superoxide formation. Br J Pharmacol 2000, 131:667-672

36. Lu Q, Zhu YZ, Wong PT: Neuroprotective effects of candesartan against cerebral ischemia in spontaneously hypertensive rats. Neuroreport 2005, 16:1963-1967.

37. Hamai M, Iwai M, Ide A, Tomochika H, Tomono Y, Mogi M, Horiuchi M: Comparison of inhibitory action. Neuropharmacology 2006, 51:822-828.

38. Rodriguez-Pallares J, Parga JA, Muñoz A, Rey P, Guerra MJ, LabandeiraGarcia JL: Mechanism of 6-hydroxydopamine neurotoxicity: the role of NADPH oxidase and microglial activation in 6-hydroxydopamineinduced degeneration of dopaminergic neurons. J Neurochem 2007, 103:145-156. 
39. Suzuki S, Brown CM, Dela Cruz CD, Yang E, Bridwell DA, Wise PM: Timing of estrogen therapy after ovariectomy dictates the efficacy of its neuroprotective and antiinflammatory actions. Proc Natl Acad Sci USA 2007, 104:6013-6018

40. Turgeon JL, Carr MC, Maki PM, Mendelsohn ME, Wise PM: Complex actions of sex steroids in adipose tissue, the cardiovascular system, and brain: Insights from basic science and clinical studies. Endocr Rev 2006, 27:575-605.

41. Morale MC, Serra PA, L'episcopo F, Tirolo C, Caniglia S, Testa N, Gennuso F, Giaquinta G, Rocchitta G, Desole MS, Miele E, Marchetti B: Estrogen, neuroinflammation and neuroprotection in Parkinson's disease: glia dictates resistance versus vulnerability to neurodegeneration. Neuroscience 2006, 138:869-878.

42. Tripanichkul W, Sripanichkulchai $K$, Finkelstein DI: Estrogen down-regulates glial activation in male mice following 1-methyl-4-phenyl-1,2,3,6tetrahydropyridine intoxication. Brain Res 2006, 1084:28-37.

43. Xue B, Zhao Y, Johnson AK, Hay M: Central estrogen inhibition of angiotensin II-induced hypertension in male mice and the role of reactive oxygen species. Am J Physiol Heart Circ Physiol 2008, 295: H1025-1032.

44. Ito K, Hirooka Y, Kimura Y, Sagara Y, Sunagawa K: Ovariectomy augments hypertension through rho-kinase activation in the brain stem in female spontaneously hypertensive rats. Hypertension 2006, 48:651-657.

45. Song J, Kost CK Jr, Martin DS: Androgens potentiate renal vascular responses to angiotensin II via amplification of the Rho kinase signaling pathway. Cardiovasc Res 2006, 72:456-463.

46. de Gasparo M, Catt KJ, Inagami T, Wright JW, Unger T: International union of pharmacology. XXIII. The angiotensin II receptors. Pharmacol Rev 2000, 52:415-472.

47. Correa FM, Viswanathan M, Ciuffo GM, Tsutsumi K, Saavedra JM: Kidney angiotensin II receptors and converting enzyme in neonatal and adult Wistar-Kyoto and spontaneously hypertensive rats. Peptides 1995, 16:19-24.

48. Ozono R, Wang ZQ, Moore AF, Inagami T, Siragy HM, Carey RM: Expression of the subtype 2 angiotensin (AT2) receptor protein in rat kidney. Hypertension 1997, 30:1238-1246.

49. Wu L, Iwai M, Nakagami H, Li Z, Chen R, Suzuki J, Akishita M, de Gasparo M, Horiuchi M: Roles of angiotensin II type 2 receptor stimulation associated with selective angiotensin II type 1 receptor blockade with valsartan in the improvement of inflammation-induced vascular injury. Circulation 2001, 104:2716-2721

50. Villar-Cheda B, Valenzuela R, Rodriguez-Perez Al, Guerra MJ, LabandeiraGarcia JL: Aging-related changes in the nigral angiotensin system enhances proinflammatory and pro-oxidative markers and 6-OHDAinduced dopaminergic degeneration. Neurobiol Aging 2010, PMID:20888078.

51. Villar-Cheda B, Rodríguez-Pallares J, Muñoz A, Valenzuela R, Guerra MJ, Baltatu OC, Labandeira-Garcia JL: Nigral and striatal regulation of angiotensin receptor expression by dopamine and angiotensin in rodents: implications for progression of Parkinson's disease. Eur $J$ Neurosci 2010, 32:1695-1706.

52. Zeng C, Liu Y, Wang Z, He D, Huang L, Yu P, Zheng S, Jones JE, Asico LD, Hopfer U, Eisner GM, Felder RA, Jose PA: Activation of D3 dopamine receptor decreases angiotensin II type 1 receptor expression in rat renal proximal tubule cells. Circ Res 2006, 99:494-500.

53. Khan F, Spicarová Z, Zelenin S, Holtbäck U, Scott L, Aperia A: Negative reciprocity between angiotensin II type 1 and dopamine $D 1$ receptors in rat renal proximal tubule cells. Am J Physiol Renal Physiol 2008, 295: F1110-1116.

54. Gildea JJ: Dopamine and angiotensin as renal counterregulatory systems controlling sodium balance. Curr Opin Nephrol Hypertens 2009, 18:28-32.

55. Sugaya T, Nishimatsu S, Tanimoto K, Takimoto E, Yamagishi T, Imamura K, Goto S, Imaizumi K, Hisada Y, Otsuka A, et al: Angiotensin II type 1a receptor-deficient mice with hypotension and hyperreninemia. J Biol Chem 1995, 270:18719-18722.

56. Paxinos $G$, Watson $C$ : The rat brain in stereotaxic coordinates. New York: Academic Press; 1985.

57. Dziuk PJ, Cook B: Passage of steroids through silicone rubber. Endocrinology 1966, 78:208-211.
58. Febo M, Ferris CF, Segarra AC: Estrogen influences cocaine-induced blood oxygen level-dependent signal changes in female rats. J Neurosci 2005, 25:1132-1136

59. Rodriguez-Perez Al, Valenzuela R, Villar-Cheda B, Guerra MJ, Lanciego IL, Labandeira-Garcia JL: Estrogen and angiotensin interaction in the substantia nigra. Relevance to postmenopausal Parkinson's disease. Exp Neurol 2010, 224:517-26.

60. Mannino CA, South SM, Inturrisi CE, Quinones-Jenab V: Pharmacokinetics and effects of 17beta-estradiol and progesterone implants in ovariectomized rats. J Pain 2005, 6:809-816.

61. Fugger HN, Foster TC, Gustafsson J, Rissman EF: Novel effects of estradio and estrogen receptor alpha and beta on cognitive function. Brain Res 2000, 883:258-264.

62. Unger T: Inhibiting angiotensin receptors in the brain: possible therapeutic implications. Curr Med Res Opin 2003, 19:449-451.

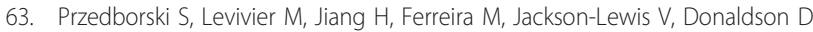
Togasaki DM: Dose-dependent lesions of the dopaminergic nigrostriatal pathway induced by intrastriatal injection of 6-hydroxydopamine. Neuroscience 1995, 67:631-647.

64. Sauer $\mathrm{H}$, Oertel WH: Progressive degeneration of nigrostriatal dopamine neurons following intrastriatal terminal lesions with 6-hydroxydopamine: a combined retrograde tracing and immunohistochemical study in the rat. Neuroscience 1994, 59:401-415.

65. Hemming ML, Selkoe DJ, Farris W: Effects of prolonged angiotensinconverting enzyme inhibitor treatment on amyloid $\beta$-protein metabolism in mouse models of Alzheimer disease. Neurobiol Dis 2007, 26:273-281.

66. Griendling KK, Minieri CA, Ollerenshaw JD, Alexander RW: Angiotensin II stimulates NADH and NADPH oxidase activity in cultured vascular smooth muscle cells. Circ Res 1994, 74:1141-1148.

67. Hong H, Zeng JS, Kreulen DL, Kaufman DI, Chen AF: Atorvastatin protects against cerebral infarction via inhibition of NADPH oxidase-derived superoxide in ischemic stroke. Am J Physiol Heart Circ Physiol 2006, 291 H2210-2215.

68. Gundersen HJG, Bendsen TF, Korbo L, Marcussen N, Moller A, Nielsen K: Some new, simple and efficient stereological methods and their use in pathological research and diagnosis. APIMS 1988, 96:379-394.

doi:10.1186/1750-1326-6-58

Cite this article as: Rodriguez-Perez et al:: Renin angiotensin system and gender differences in dopaminergic degeneration. Molecular Neurodegeneration 2011 6:58.

\section{Submit your next manuscript to BioMed Central and take full advantage of:}

- Convenient online submission

- Thorough peer review

- No space constraints or color figure charges

- Immediate publication on acceptance

- Inclusion in PubMed, CAS, Scopus and Google Scholar

- Research which is freely available for redistribution

Submit your manuscript at www.biomedcentral.com/submit
Ciomed Central 